\title{
CONHECER AS CORES SEM NUNCA TÊ.LAS VISTO
}

\author{
Cristina Bianchi* \\ Kim Ramos** \\ Maria da Conceição Barbosa-Lima***
}

RESUMO: Ensinar cores a cegos de nascimento é um desafio para professores de física, porém insistimos em fazê-lo. Propomos levar em consideração que todos os sentidos são mobilizados no processo de aprendizagem, sendo assim, multissensorial. O sentido da visão, em nosso caso de estudo, será substituído por outros. Considerando que a formação de conceitos é um processo sociolinguístico, avaliamos e averiguamos o conteúdo imagético do conceito de cores em um teste de associação livre com estudantes cegos e videntes. Concluímos que tais conceitos não dependem exclusivamente do visual; outras associações estão envolvidas na sua construção, embora saibamos que nenhum outro sentido fará um cego perceber visualmente as cores. Assim, é possível uma concepção segundo a qual o ensino de cores a alunos cegos deixe de ser um desafio intransponível.

Palavras-chave: Cegos totais de nascimento. Cores. Aprendizado multissensorial.

\section{CONOCIENDO LOS COLORES SIN NUNCA HABERLOS VISTO}

RESUMEN: Enseñar los colores a ciegos de nacimiento es un desafío para maestros de física, pero insistimos en hacerlo. Propusimos llevar en consideración que todos los sentidos son movilizados en el proceso de aprendizaje, siendo plurisensorial. El sentido de la visión, en nuestro caso de estudios, será sustituido por otros. Considerando que la formación de conceptos es un proceso socio-lingüístico, evaluamos y averiguamos que el contenido de imágenes del concepto de colores en un test de conceptos no depende exclusivamente del visual. Otras asociaciones están involucradas en su construcción, aunque sepamos que ningún otro sentido hará que un ciego perciba visualmente los colores. Así, es posible una concepción en la que la enseñanza de los colores a alumnos ciegos deje de ser un desafío imbatible.

Palabras clave: Ciegos totales desde el nacimiento. Colores. Aprendizaje multisensorial.
*Universidade do Estado do Rio de Janeiro (UERJ) Rio de Janeiro, RJ - Brasil Licenciada e Mestra em Biologia pela Universidade do Estado do Rio de Janeiro (UERJ).

Mestre em Biociências Nucleares pela Universidade do Estado do

Rio de Janeiro, professora na

área do ensino de Ciências e da formação Docentes em Física, com o projeto intitulado "Concepções de Licenciandos sobre o ensino de Física a alunos com Deficiência Visual", no Instituto Benjamin Constant, no Rio de Janeiro (IBC). crisbianchibr@yahoo.com.br

* * * Universidade do Estado do Rio de Janeiro (UERJ) Rio de Janeiro, RJ - Brasil Aluno de graduação em licenciatura em Física do Instituto de Física Armando Dias Tavares, da UERJ, e bolsista de Iniciação Científica da FAPERJ. prof.kim.ramos@gmail.com

**** Universidade do Estado do Rio de Janeiro (UERJ) Rio de Janeiro, RJ - Brasil Doutora em Educação pela FEUSP, professora associada do Instituto de Física Armando Dias Tavares, da UERJ. E-mail: mcablima@uol.com.br 


\section{TO KNOW THE COLORS WITHOUT EVER HAVING SEEN THEM}

ABSTRACT: Teaching colors to blind students has been a challenge for physics teachers. However, we insist on trying to do so, considering that all senses are mobilized in the learning process and that concept formation is a sociolinguistic process. In this manner, the sense of sight, lacking in our case study, can be replaced by others in multisensorial learning. We evaluated imagistic content about the color concept and ascertained its multisensory origin in a free association test with blind and sighted students. Although any other sense could ever make a blind person visually perceive colors, we conclude that the concept of color depends not only on the sense of sight, and that other associations are involved in their significance construction. Thus, it is possible that teaching colors to blind students can stop being such an unbeatable challenge.

Keywords: Total blindness from birth. Colors. Multisensorial learning. 


\section{INTRODUĈ̣̃O}

A questão "De que maneira deve se dar o ensino de cores para alunos totalmente cegos de nascimento?" (CAMARGO, 2012, p. 267) constitui grande desafio para o ensino de física. Reforçamos a assertiva com as respostas que obtivemos de professores de física que ministram aulas em escolas regulares a partir de uma questão que propusemos: “Que conceitos da física são exclusivamente dependentes da percepção visual para sua compreensão?” A grande maioria (80\%) respondeu "cores", mas há alguns que creem que nenhum conceito em física é exclusivamente dependente da percepção visual para o aprendizado.

Estamos cientes de que a primeira questão desafiadora não deve propor uma única resposta, mas caminhos possíveis que nos façam ampliar nossos referenciais para a educação científica de pessoas com deficiência visual. Contudo, antes de pensar em formas de ensinar, é preciso conhecer formas de aprender, uma vez que o ensino-aprendizagem é uma díade e, assim sendo, inseparável, principalmente se considerarmos o papel de destaque que o aprendiz exerce nesse contexto. Iluminando a idiossincrasia do processo, partimos do princípio de que toda aprendizagem se dá por meio do ativo envolvimento do estudante na construção do conhecimento, como também de que suas ideias prévias desempenham um papel importante no processo de aprendizagem (DRIVER et al., 1994; DUIT, 1996; MAURI, 2006). Essas são as condições de uma aprendizagem significativa, ou seja, que possua significado, tornando-se relevante na vida dos indivíduos.

Se recorrermos a Vigotski em sua obra de 2007, a de Luria de 2006, veremos que nada pode existir em nossa consciência sem uma significação, isto é, sem um movimento interno ativo de produção de significados, que, por sua vez, vai ao encontro de um senso comum. Essa representação mental, com a qual explicamos o mundo em que vivemos, em si, não é o significado, mas a ele se relaciona por meio das associações construídas, além de outras funções intelectuais: A formação dos conceitos é resultado de uma complexa atividade em que todas as funções
intelectuais fundamentais participam. No entanto, este processo não pode ser reduzido à
associação, à tendência, à imagética, à inferência ou às tendências determinantes. Todas
estas funções são indispensáveis, mas não são suficientes se não se empregar o signo ou a
palavra, como meios pelos quais dirigimos as nossas operações mentais, controlamos o seu
curso e o canalizamos para a solução do problema com que nos defrontamos (VIGOT-
SKI, 2001).

Ainda segundo Vigotski (2001, p. 104):

O significado duma palavra representa um amálgama tão estreito de pensamento e linguagem que é difícil dizer se se trata de um fenômeno de pensamento ou se se trata de um fenômeno de linguagem. Uma palavra sem significado é um som vazio; portanto, o significado é um critério da palavra e um seu componente indispensável.

A percepção visual tem sido conceituada como o sentido privilegiado para a produção de representações mentais. No entanto, audição, olfato, paladar e tato 
contribuem simultaneamente na produção dessas representações. Conhecimentos e aprendizagens produzidos sob uma perspectiva basicamente visual são considerados incompletos (SOLER, 1999), já que qualquer processo de significação pode ser considerado multissensorial por excelência; não privamos estímulos sensoriais em favor de alguma percepção específica no contato com o mundo.

Tendo isso em mente, propomos uma reflexão sobre o significado das cores e a importância de seu estudo antes de desenvolvermos nossa tese de que, para o ensino de cores a alunos cegos de nascença, é preciso conhecer primeiramente suas concepções acerca do assunto. Para tal, realizamos um teste de associação livre de palavras (MERTEN, 1992) com estudantes cegos e com estudantes videntes.

\section{O SIGNIFICADO DAS CORES}

Iniciemos nossa reflexão com a questão: Se nossa visão fosse em "preto e branco", teríamos descoberto o espectro proveniente da luz branca? Induzimos uma resposta positiva, já que radiações invisíveis a nossos olhos foram descobertas ainda no início do século XIX: em 1800 a luz infravermelha foi descoberta por Willian Herschel (FIOLHAIS, 2015), e, em 1801, os raios químicos de Johann Ritter, ou raios ultravioletas, que escureceram seu cloreto de prata, foram identificados. A descoberta de Oersted sobre a relação entre magnetismo e eletricidade, por exemplo, impulsionou novos rumos de investigação científica, sendo profundamente influenciada por ideias metafísicas, a literatura e a filosofia (GUERRA; REIS; BRAGA, 2004).

Embasados na necessidade de superar uma visão mecanicista, nossas reflexões nos levam a buscar uma visão integrada sobre o significado das cores. Nossa abordagem não se mantém exclusivamente em um domínio "fisicalista" ou mecanicista (HILBERT, 1987), segundo o qual as cores seriam propriedades físicas dos objetos (reflectância das superfícies), nem em uma exclusividade "subjetivista" (HARDIN, 1998), que considera as cores como produto de um processamento mental. Nossa discussão se amplia de uma visão "psicofisicalista" (SAVAGE, 2001), de acordo com a qual a percepção de cores se dá no desenvolvimento de sensibilidades sensoriais adaptativas selecionadas naturalmente no curso da evolução dos seres, em uma visão que denominamos "sociopsicofisicalista", considerando uma proposta que culmine em questões epistemológicas que contribuam para a formação científica de alunos cegos, inclusive.

Pensando em termos evolutivos, a visão em cores, ao proporcionar vantagens adaptativas a ancestrais humanos, pode também ter selecionado sensações desencadeadas pela sua percepção visual (MATSUSHIMA, 2001). Temos hoje sensações de estímulo por cores que denominamos "quentes" e sensações de tranquilidade por cores que denominamos "frias". É possível que uma diversidade de sensações em relação às mesmas cores, diferentes das que temos hoje, possa ter existido, mas não ter conferido vantagem adaptativa a nossos ancestrais. Aqui está dada a ideia primordial para que reconheçamos a relatividade da significação das cores e sua dependência de uma concepção humana. 
Pensemos, agora, na cor vermelha. Que representação geramos mentalmente? Possui característica universal? Sem nos aprofundarmos na fisiologia sensorial, adiantamos que nossas percepções diferem qualitativamente das propriedades físicas do estímulo em si. Sendo assim, o que é "vermelho" e qual a importância desse questionamento para a aprendizagem de física sobre cores?

Quando pronunciamos a palavra "vermelho", a pessoa vidente produz uma representação mental, que é a representação de um estímulo que impressionou as próprias células fotossensíveis da retina, transformado-se em impulso elétrico para ser conduzido e interpretado em nível cerebral. Sartre (2013, p. 124), em uma leitura da fenomenologia de Husserl, nos diz:

Esta impressão visual que presentemente faz parte de minha consciência não é o vermelho. O vermelho é uma qualidade do objeto, uma qualidade transcendente. A impressão subjetiva que, sem dúvida, é "análoga" ao vermelho da coisa à apenas um "quase vermelho", ou seja, é a matéria subjetiva, a "hylé" sobre a qual se aplica a intenção que se transcende e busca atingir o vermelho fora de si.

Descartamos, assim, qualquer ideia de processo passivo na produção das representações mentais e questionamos se a representação específica produzida por um estímulo luminoso é pré-requisito insubstituível para a compreensão e a aprendizagem sobre cores.

No contexto vidente, "vermelho", ao ser lido ou ser pronunciado, suscita uma imagem mental que é a representação do estímulo, isto é, a ideia de vermelho, mas que não significaria nada se a experiência do indivíduo com esse estímulo não tivesse passado por um processo de significação desde a infância, quer dizer, uma resposta cortical a determinados comprimentos de onda luminosa não possui significado per se, antes, o conceito é aprendido socialmente.

Ao perguntamos "o que é o vermelho?", associações são estabelecidas de imediato. A palavra "cor" é uma das primeiras a aparecer, enquanto outras ideias podem surgir quando perguntamos "o que vem à sua mente ao ouvir a palavra 'vermelho'?". As cores estão ligadas a associações construídas socialmente, e um exemplo de como operamos associativamente e multissensorialmente nosso conhecimento são alguns testes sinestésicos que demonstram a associação entre cores e sons, em que cores elicitam sons e vice-versa (GOLLER; OTTEN; WARD, 2009). Evidências da psicologia cognitiva também sugerem que a experiência, a linguagem e as estruturas neuronais visuais contribuem na representação mental de cores (SHEPARD; COOPER, 1992), afastando a ideia de que "cores" possuem uma representação exclusiva da percepção visual.

Contudo, não afirmamos que outras percepções sensórias, como a audição ou o olfato, sejam capazes de veicular a informação visual da cor, como observamos na ideia fisiológica de substituição de função de órgãos pares, presente até o início do século XX (VIGOTSKI, 1997). Camargo (2012) corrobora essa perspectiva em seu conceito de "indissociabilidade" relativa à categoria linguística elaborada por ele, a semântico-sensorial. Esta diz respeito aos efeitos produzidos pela percepção sensorial nos significados de conceitos e fenômenos. Segundo o autor, significados indissociáveis "são aqueles cuja representação mental é depen- 
dente de determinada percepção sensorial. Esses significados nunca poderão ser representados internamente por meio de percepções sensoriais distintas das que os constituem.” (CAMARGO, 2012, p. 47).

\section{IMPORTÂNCIA DO ESTUDO DAS CORES}

Simultaneamente à compreensão de que o conhecimento científico é resultado de construções sociais, introduzir os estudantes na complexa natureza da luz pode se tornar fundamental para o desenvolvimento do raciocínio científico, caracterizado por um pensamento crítico, investigativo, dedutivo, indutivo e, principalmente, criativo. As contribuições de Hertz, Einstein, Bohr e Planck devem ser lembradas, e a contextualização com fenômenos fotoelétricos no dia a dia é indispensável.

Conceitos de fóton, quantum, dualidade onda/partícula, ondas, frequência etc. são todos invisíveis aos olhos e possíveis de ser representados por modelos. Dentro dessa perspectiva, o ensino de cores pode oportunizar o levantamento de questões que demonstrem alcances e limitações da ciência (SANDOVAL, J. D.; SANDOVAL, J. J., 1990), como:

- a objetividade da ciência é suficiente para explicar o que são as cores?

- o conhecimento científico que o ser humano tem sobre as cores é definitivo?

- a visão das cores é exclusivamente necessária para compreender seu significado científico?

- a visão das cores é exclusivamente necessária para compreender seu significado social?

- todas as pessoas enxergam as cores da mesma maneira?

- existem cores sem sujeitos que as visualizem?

Por isso, um estudo das cores pode contribuir na formação do aluno crítico, pronto a exercer seu papel social em colaboração com uma sociedade voltada ao desenvolvimento humano (BIANCHI; BARBOSA-LIMA, 2014).

\section{METODOLOGIA}

Em nossa abordagem qualitativa, aplicamos um teste de associação livre de palavras (MERTEN, 1992) em nove estudantes cegos desde o nascimento, com idade entre 16 e 24 anos, e em 72 estudantes videntes, com idades entre 16 e 21 anos. A variável chamada "comunalidade", que examina quantas vezes uma resposta particular foi dada por um grupo de pessoas, foi avaliada, de modo a estabelecer as palavras mais comuns entre os grupos. Pedimos aos estudantes que escrevessem a primeira palavra ou ideia que lhes 
viesse à mente quando pensavam nas cores: branca, verde, vermelha, azul, preta, amarela, laranja e cinza.

Nossa amostra tem uma variação bastante peculiar, pelo simples fato de não ser fácil o acesso a pessoas cegas desde o nascimento que se voluntariem para a participação em uma pesquisa. Sendo assim, contamos com um estudante cego que cursava o quarto período em Direito em uma universidade e outros oito que cursavam o $9^{\circ}$ ano do Ensino Fundamental, em uma escola especializada. Todos os estudantes videntes, de mais fácil acesso, cursavam o $3^{\circ}$ ano do Ensino Médio em um colégio estadual regular do Rio de Janeiro. Dados dos estudantes encontram-se nas tabelas 1 e 2 , a seguir:

Tabela 1: Idades dos estudantes videntes

\begin{tabular}{|c|c|}
\hline IDADE DOS ESTUDANTES & NÚMERO DE ESTUDANTES \\
\hline 16 & 1 \\
\hline 17 & 32 \\
\hline 18 & 30 \\
\hline 19 & 6 \\
\hline 20 & 1 \\
\hline 21 & 2 \\
\hline Total & 72 \\
\hline
\end{tabular}

Fonte: Dados da pesquisa.

Tabela 2: Dados dos estudantes cegos

\begin{tabular}{|c|c|c|c|c|}
\hline ALUNO & IDADE & ESCOLARIDADE & MOTIVO DA CEGUEIRA & $\begin{array}{c}\text { PERCEPC̃̃̃ O } \\
\text { DE CORÉS }\end{array}$ \\
\hline A1 & 16 & $9^{\circ}$ ano & Retinopatia da prematuridade & Sim \\
\hline A2 & 16 & $9^{\circ}$ ano & $\begin{array}{r}\text { Assiridia, glaucoma e catarata } \\
\text { congênita }\end{array}$ & Sim \\
\hline A3 & 17 & $9^{\circ}$ ano & $\begin{array}{c}\text { Deslocamento da retina e atrofia do } \\
\text { nervo ótico congênito }\end{array}$ & Sim \\
\hline A4 & 17 & $9^{\circ}$ ano & Gim \\
\hline A5 & 18 & $9^{\circ}$ ano & Retinoblastoma congen 1 ano e 7 & Não \\
\hline A6 & 19 & $9^{\circ}$ ano & Glaucoma congênito & Sim \\
\hline
\end{tabular}




\begin{tabular}{|c|c|c|c|c|}
\hline A7 & 22 & $9^{\circ}$ ano & Glaucoma congênito & Sim \\
\hline A8 & 22 & Universitário & Glaucoma congênito & Sim \\
\hline A9 & 24 & $9^{\circ}$ ano & $\begin{array}{c}\text { Endotropia com nistagmo congê- } \\
\text { nito }\end{array}$ & Não \\
\hline
\end{tabular}

Fonte: Dados da pesquisa.

Esclarecemos que a caracterização da condição denominada "cegueira" se deve ao grau de percepção visual normatizado pelo Decreto 5.296/04, que afirma que, quando a acuidade visual no melhor olho, com a maior correção óptica possível, é igual ou menor que 20/400 (0,05) - o quer dizer que a pessoa enxerga a 20 metros o que um olho normal enxergaria a 400 metros -, a pessoa é considerada cega, mesmo tendo percepção de alguma luminosidade (BRASIL, 2004). A situação de ausência completa de percepção luminosa é denominada com um termo médico chamado "amaurose". Em nosso estudo, apenas o aluno A5 estava dentro da condição de amaurose; o aluno A9 percebia luminosidade (claro e escuro), mas não as cores; e os outros sete alunos percebiam luminosidade e cores, mas apenas em situação de forte luminosidade, como, por exemplo, quando a iluminação ambiente fosse superior a 200 watts (considerando um cômodo de 9m2). Lembrando que a cegueira pode ser caracterizada, no que se refere ao momento da sua instalação, em congênita (se surge de 0 a 1 ano de idade); precoce (se surge entre o primeiro e o terceiro ano de idade); adquirida (se surge após os 3 anos de idade).

$\mathrm{Na}$ cegueira congênita não existem referenciais visuais (imagem mental), e, desse modo, o paciente possui uma representação intelectualizada do ambiente (cores, perspectivas, volumes, relevos) sem possuir um conceito visual. Na cegueira adquirida, o paciente dispõe de todo o patrimônio visual anterior à cegueira, e, por isso, existe a capacidade de representação de um objeto ou de um ambiente por analogia. A cegueira parcial (também referida como legal ou profissional) engloba os pacientes apenas capazes de contar dedos a uma curta distância e os que só percebem vultos.

Mais próximos da cegueira total estão os pacientes que apenas apresentam percepção da luz ou de projeções luminosas. No primeiro caso, há apenas a distinção entre claro e escuro; no segundo (projeção), o indivíduo é capaz de identificar a direção de onde provém a luz. A cegueira total, ou amaurose, por sua vez, corresponde à perda completa de visão.

Gráficos comparativos das ideias mais comuns entre estudantes cegos e videntes são analisados nos resultados e apoiam nossa discussão.

\section{RESULTADOS}

Nos gráficos 1 a 8, verificamos as ideias associadas pelo grupo de alunos videntes às cores branca, verde, vermelha, azul, preta, amarela, laranja e cinza. Os 
gráficos 9 e 10 representam as associações feitas pelos alunos cegos, e o Quadro 1 mostra as ideias apenas dos alunos que não possuem percepção de cores (A5 e A9).

Gráfico 1: Ideias mais comuns associadas à cor branca pelo grupo vidente

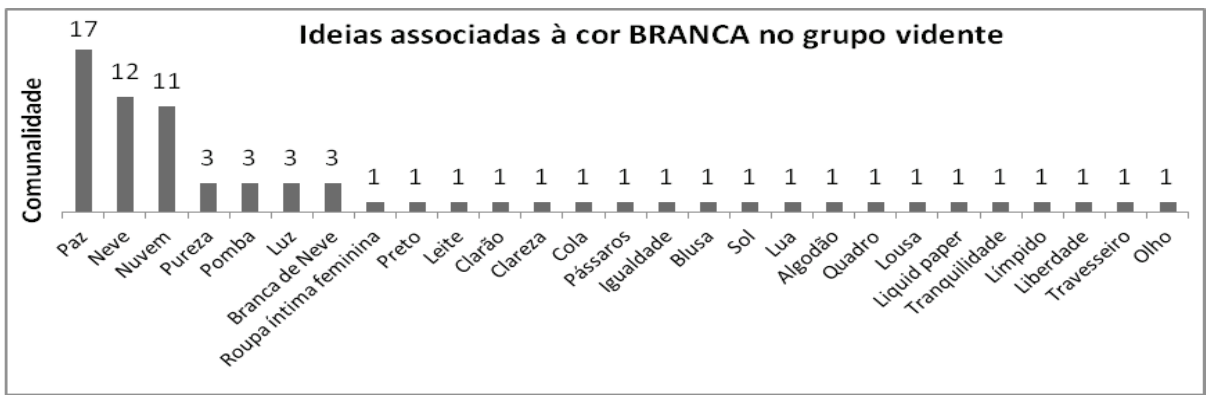

Fonte: Elaboração pelos autores deste artigo.

Gráfico 2: Ideias mais comuns associadas à cor verde pelo grupo vidente

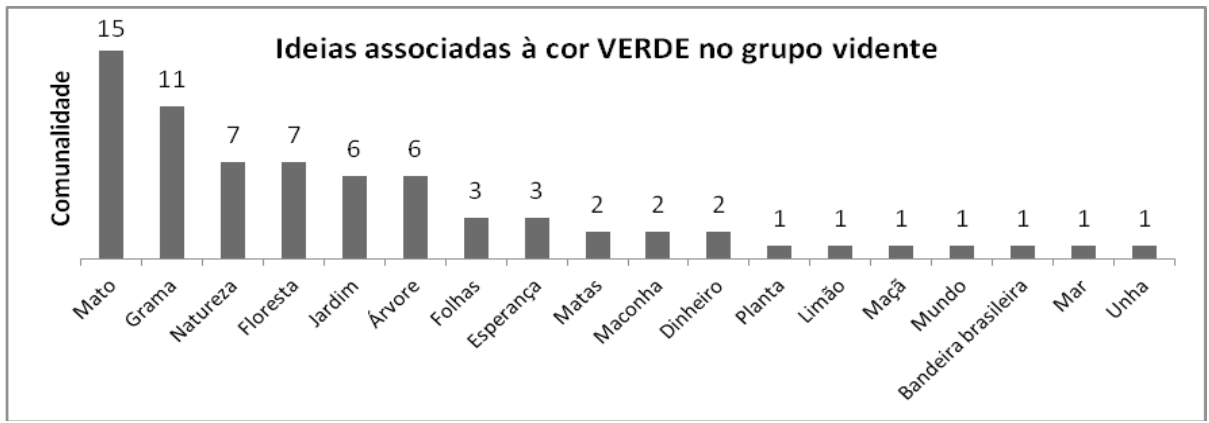

Fonte: Elaboração pelos autores deste artigo.

Gráfico 3: Ideias mais comuns associadas à cor vermelha pelo grupo vidente

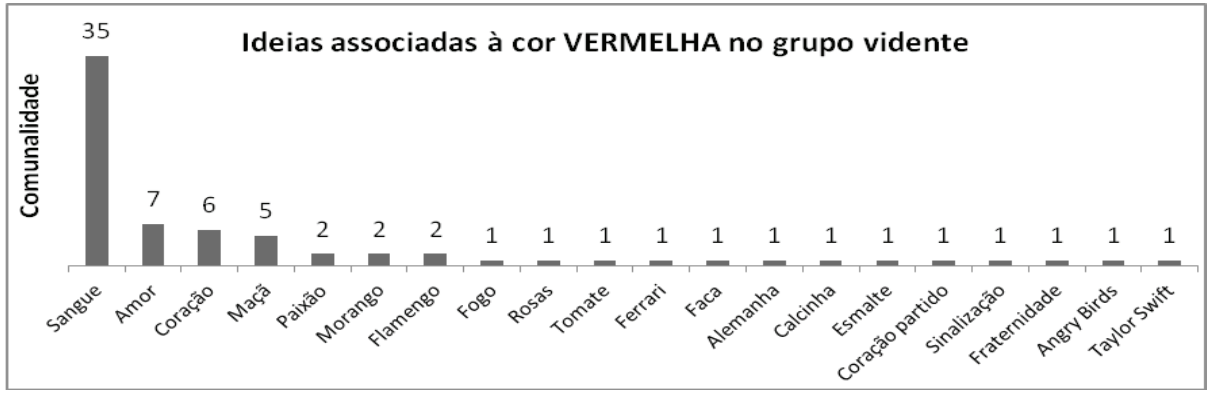

Fonte: Elaboração pelos autores deste artigo. 
Gráfico 4: Ideias mais comuns associadas à cor azul pelo grupo vidente

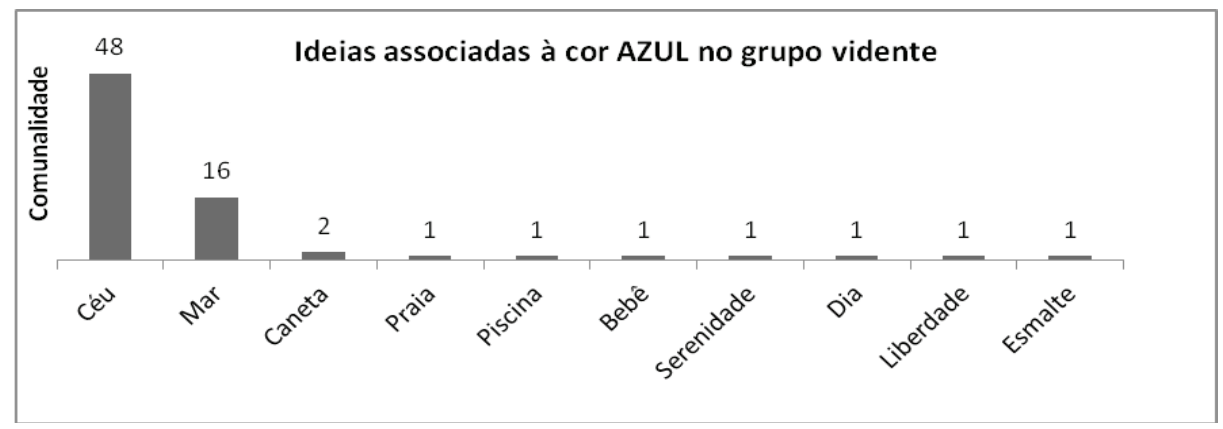

Fonte: Elaboração pelos autores deste artigo.

Gráfico 5: Ideias mais comuns associadas à cor preta pelo grupo vidente

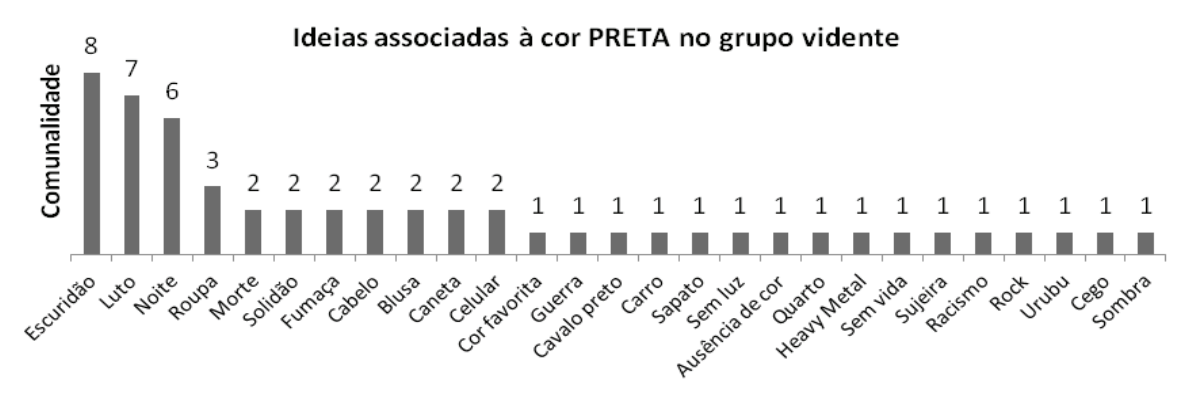

Fonte: Elaboração pelos autores deste artigo.

Gráfico 6: Ideias mais comuns associadas à cor amarela pelo grupo vidente

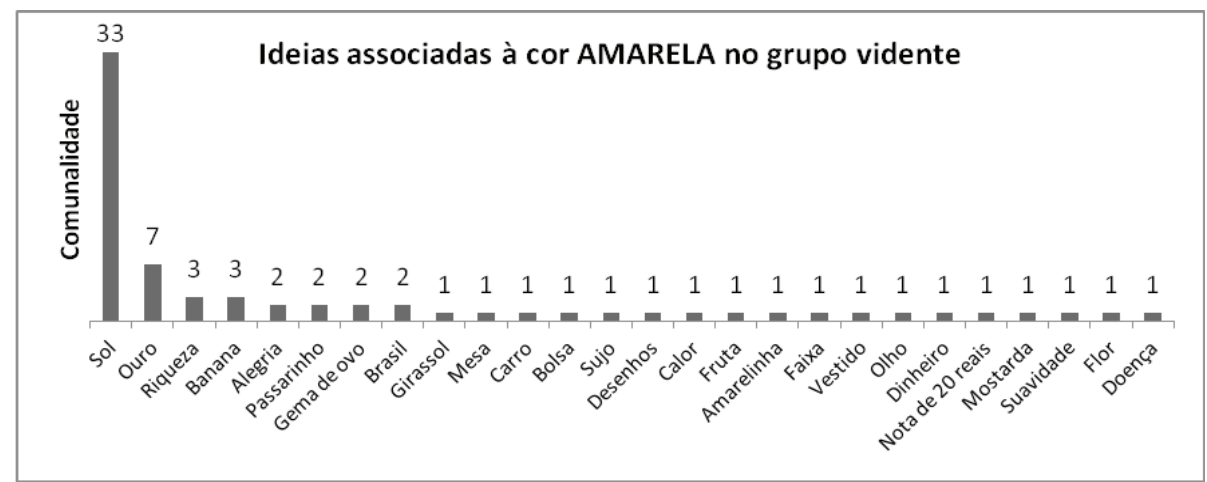

Fonte: Elaboração pelos autores deste artigo. 
Gráfico 7: Ideias mais comuns associadas à cor laranja pelo grupo vidente

Ideias associadas à cor LARANJA no grupo vidente

Gráfico 8: Ideias mais comuns associadas à cor cinza pelo grupo vidente

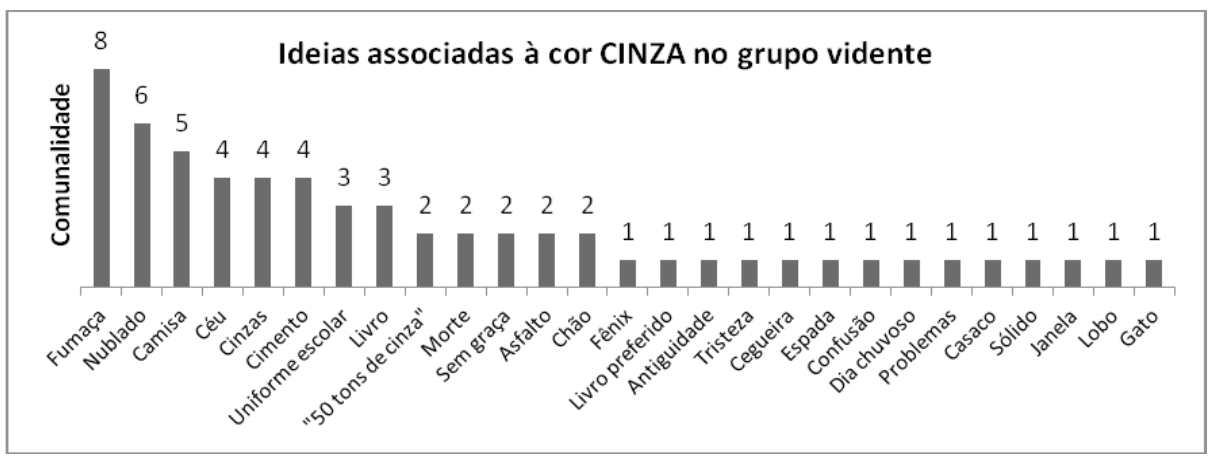

Fonte: Elaboração pelos autores deste artigo.

Gráfico 9: Ideias mais comuns associadas às cores branca, verde, vermelha e azul pelo grupo de cegos

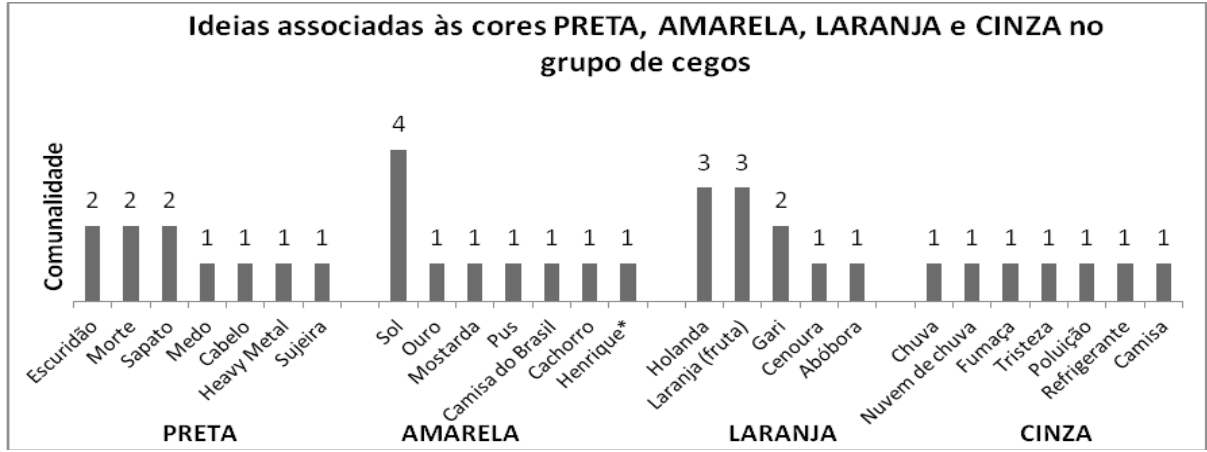


Gráfico 10: Ideias mais comuns associadas às cores preta, amarela, laranja e cinza pelo grupo de cegos

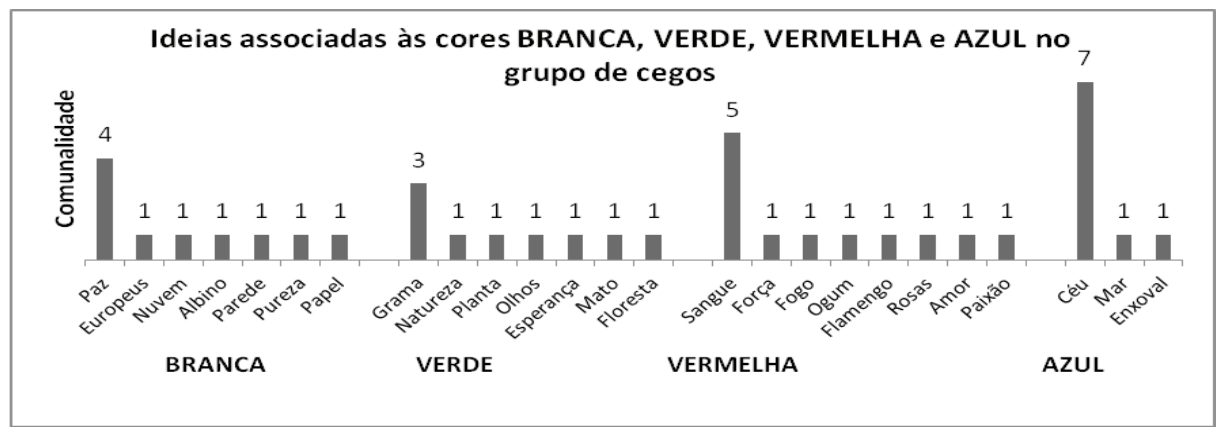

Fonte: Elaboração pelos autores deste artigo.

Quadro 1: Associações dos alunos sem percepção de cores

\begin{tabular}{|c|c|c|c|c|c|c|c|c|}
\hline $\begin{array}{c}\text { COR/ } \\
\text { ALUN0 }\end{array}$ & BRANCO & VERDE & VERMELHA & AZUL & PRETA & AMARELA & LARANJA & CINZA \\
\hline A5 & Albino & Grama & Sangue & Mar & $\begin{array}{c}\text { Heavy } \\
\text { Metal }\end{array}$ & Henrique* & $\begin{array}{c}\text { Laranja } \\
\text { (fruta) }\end{array}$ & Camisa \\
\hline A9 & Pureza & Floresta & Sangue & Céu & $\begin{array}{c}\text { Morte, } \\
\text { sujeira }\end{array}$ & Cachorro & $\begin{array}{c}\text { Laranja } \\
\text { (fruta) }\end{array}$ & $\begin{array}{c}\text { Polui- } \\
\text { ção }\end{array}$ \\
\hline
\end{tabular}

Fonte: Elaboração pelos autores deste artigo.

Podemos verificar em nossos resultados que as ideias que os alunos cegos associam às cores (gráficos 9 e 10) são as mesmas dos alunos videntes (gráficos de 1 a 8), com forte equivalência de comunalidade, ou seja, de respostas comuns entre os grupos, sobretudo o dos alunos sem percepção alguma de cor (Quadro 1).

Um fato interessante a ressaltar é que, apesar de o aluno A5 (com amaurose) não poder visualizar o colega de classe Henrique (nome fictício), que é albino, o associa à cor amarela, uma forma espirituosa de se referir a ele. Já o aluno A9 associa a cor amarela a seu próprio cachorro, pois na infância havia ficado curioso e questionado a cor de seu cão.

\section{DISCUSSÃO}

As associações dos alunos (cegos e videntes) às cores demonstram componentes subjetivos e multissensoriais. Paz, algodão, limão, sangue, amor, rosas, céu, mar, serenidade, escuridão, luto, morte, fumaça, sol, ouro, riqueza, laranja, Holanda, nublado, camisa, tristeza, cegueira; percepções táteis, auditivas, gusta- 
tivas, olfativas e emocionais, além das visuais, são mobilizadas no processo de aprendizagem das cores desde a infância, já que a estratégia para o ensino de cores na educação infantil é a associação. Um pequeno trecho do livro infantil Jonas e as cores, de Regina Berlim (2007), escrito sobre um fundo ilustrado em vermelho, corrobora nossa assertiva: "Do VERMELHO, Jonas levou o doce de morango, a dor e o gosto de sangue de um cortezinho de nada na ponta do dedo, o forte perfume das rosas. Suco de groselha com açúcar e tomate com sal, uma joaninha atrevida na palma da mão, que é prá dar sorte.” (BERLIM, 2007, p. 26).

A dificuldade em pensar no ensino de cores a alunos cegos de nascimento surge da concepção de que a impossibilidade de captar estímulos luminosos através da retina impede essas pessoas de saberem sobre cores. Em nossos resultados, demonstramos que esses alunos apenas não percebem as cores visualmente, o que não os impede de aprendê-las, não apenas verbalmente, mas sendo capazes de estabelecer relações sociais e multissensoriais, como acontece com os videntes. $\mathrm{O}$ próprio relato dos alunos cegos deste estudo é que são capazes de aprender cores mediante o ouvir o que as pessoas dizem sobre elas. Certamente, esse não é um mero processo imitativo, uma vez que, para o estabelecimento desses conceitos, é necessária uma interação com suas experiências prévias, suas subjetividades.

Tanto o conceito quanto as ideias vinculadas são um constructo social associado à imagem, o que é partilhado entre os indivíduos culturalmente. Sem as associações, não teria sido possível a cegos nem a videntes aprender cores, uma vez que uma representação mental não possui significado exclusivo. Por isso, o ensino de cores a alunos cegos de nascimento sem percepção visual destas não se inicia quando entram em contato com a disciplina de física (em sua maioria, no $9^{\circ}$ ano do Ensino Fundamental), mas desde a infância. Esse fato, esclarecido aos professores de física, pode se tornar instrumento precioso na superação de barreiras comunicacionais entre docentes e alunos com deficiência visual (CAMARGO, 2010, 2012).

O relato da pedagoga deficiente visual Luciane Maria Molina Barbosa encontrado no site "Guia inclusivo" (MOLINA, 2013) sobre o simbolismo próprio das cores para cada pessoa, vidente ou não, complementa nossa discussão:

Para quem não enxerga não é diferente. As cores vão ganhar significados reais através de
associações táteis, olfativas e até gustativas, em alguns casos. O que diferencia, então é o
fato das abstrações deixarem de ser visuais e passarem a usar o próprio repertório já cons-
truído pela pessoa cega, por meio das texturas, dos aromas e dos gostos que já conhecem.

As associações do aluno A5 com seu colega de classe e do aluno A9 com seu cachorro, como também a da aluna vidente com a mesa ${ }^{1}$ (Gráfico 6) compartilham associações emocionais, componente subjetivo fortemente associado a todos os sentidos do organismo.

A autora Molina (2013) prossegue ainda explicando como funcionam as associações:

Para explicar, de maneira simplificada, como funciona uma associação imagética, pense no seguinte: as estrelas que aparecem no céu pela noite não se assemelham em nada com as es- 
trelas que desenhamos para representá-las, com 5 ou 6 pontas triangulares. Esses desenhos, então, são simbólicos, mas, onde quer que estejam estampados, identificamos que é uma estrela. É assim também com as demais associações que, mesmo abstratas fisicamente, ou seja, invisíveis ao olhar, representam algo que pode transportar uma imagem/simbolismo à memória. Ou seja, transformam texturas, aromas e sabores em algo palpável, criando imagens mentais de algo já conhecido e ativadas pelos sentidos das pessoas que não dispõem da visão como canal predominante de acesso às informações.

Dizer ao cego as cores de determinado ambiente, estimulá-lo a saber que cor está usando em suas roupas, que cores combinam ou não, nossas cores preferidas, cores tranquilizantes ou estimulantes, é o partilhar de uma cultura, ou seja, também é inclusão.

É preciso superar a concepção fortemente ligada ao ensino de física de que cegos não sabem nada sobre cores, sendo incapazes de aprendê-las. Ao chegarem ao $9^{\circ}$ ano do Ensino Fundamental, os estudantes cegos sem percepção de cores de nosso estudo demonstraram possuir conhecimento suficiente sobre o assunto para vencer uma das maiores barreiras educacionais no contexto do ensino de física para deficientes visuais: a já mencionada barreira comunicacional (CAMARGO, 2010, 2012).

Com base em uma concepção de construção multissensorial dos significados, sejam eles sociais ou físicos, o conhecimento sobre cores pode ser comunicado aos cegos de nascimento e por eles compreendido. Todo o conhecimento é construído socialmente como resultado de uma complexa atividade de funções intelectuais (VIGOTSKI, 2001), tendo-se na multissensorialidade uma condição ontológica.

Projeções de ondas luminosas sobre a retina e levadas ao cérebro são sensações que não podem ser vivenciadas por pessoas totalmente cegas de nascimento, quer dizer, são indissociáveis de representação visual (CAMARGO, 2012), mas adquirem significado no convívio social (VIGOTSKI, 1997). Ouvir, tatear, degustar, cheirar, sentir não podem fazer o cego ter uma experiência visual das cores, mas o conduzem a uma representação mental, de modo que o significado será atribuído de acordo com a cultura compartilhada (LURIA, 2006).

Luria (2006, p. 48), ao estudar a percepção e a classificação das cores por vários grupos de origem socioeconômica diferente, questionando se a linguagem e as atitudes práticas provocam mudanças na maneira como as pessoas as percebem, encontrou que "o pensamento classificatório não é apenas um reflexo da experiência individual, mas uma experiência partilhada, que a sociedade pode comunicar através de seu sistema linguístico”.

\section{CONSIDERACְ̃̃ES FINAIS}

Nosso esforço no presente artigo foi responder algumas questões que foram levantadas em pesquisas recentes sobre o ensino de física a alunos com deficiência visual. "De que maneira deve se dar o ensino de cores para alunos totalmente cegos de nascimento?” (CAMARGO, 2012, p. 267). A hipótese que 
formulamos em nossas reflexões surgiu de uma discussão sobre um conjunto de respostas que obtivemos com outra questão, formulada por nós a professoras e professores de física: "Que conceitos da física são exclusivamente dependentes da percepção visual para sua compreensão?”.

O que nos motivou ao questionamento foi o entendimento de que a busca pelo protagonismo do aluno deficiente visual no processo de ensino-aprendizagem é uma tarefa urgente da formação de professores de física inclusivistas (DANIEL; DAVID, 2006; BARBOSA-LIMA; CATARINO, 2013; BIANCHI; BARBOSA-LIMA, 2014). Colocando isso em prática, nos aprofundamos na reflexão sobre o papel que possui o conhecimento prévio de alunos cegos em sua aprendizagem e nos direcionamos a formas de ensinar em consonância com essa resposta: a busca de uma aprendizagem significativa, na qual a multissensorialidade cumpre papel fundante na origem das representações mentais (CORNOLDI; VECCHI, 2000) e na construção de conceitos, ou seja, de significados. Reforçamos que, apesar de a percepção visual ter sido privilegiada para a produção de representações mentais, contribuem simultaneamente na produção destas a audição, o olfato, o paladar e o tato; não privamos nossos sentidos em favor de algum específico no contato com o mundo.

Desse modo, os significados, para serem estabelecidos, passam por um processo de construção a partir de vivências compartilhadas (VIGOTSKI, 2007; LURIA, 2006). Sendo assim, nada pode existir em nossa consciência sem uma significação, isto é, sem um movimento interno ativo de produção de significados.

Tendo em mente esses pressupostos, investigamos as ideias associadas a algumas cores por alunos videntes e cegos de nascimento. Avaliamos os conteúdos imagéticos que estão na estrutura do conceito de cada cor e averiguamos sua origem multissensorial realizando um teste de associação livre de palavras (MERTEN, 1992). Além disso, refletimos sobre o significado das cores e a importância de seu estudo.

Iniciamos a nossa reflexão sobre o significado de cor com a questão: se nossa visão fosse em "preto e branco", teríamos descoberto o espectro proveniente da luz branca? Respondendo positivamente, lembramos que os descobrimentos dos raios ultravioletas e dos raios infravermelhos - espectros eletromagnéticos invisíveis - se deram ainda no século XIX. Uma nova abordagem sociológica influenciou o avanço da ciência nesse período, opondo ao mecanicismo racionalista uma leitura orgânica mais integrada com a natureza, que passava a enxergar o conhecimento humano como obra das inúmeras relações de mulheres e homens com a natureza, com a sociedade e consigo mesmos.

Nossa abordagem amplia uma visão "psicofisicalista” (SAVAGE, 2001), segundo a qual a percepção de cores se dá no desenvolvimento das relações sensoriais adaptativas selecionadas naturalmente no curso da evolução dos seres, a uma visão que denominamos "sociopsicofisicalista", considerando uma proposta que culmine em questões epistemológicas que contribuam na formação científica de alunos cegos, inclusive. Não se mantém exclusivamente em um domínio "fisicalista" ou mecanicista (HILBERT, 1987), de acordo com o qual as cores seriam propriedades físicas dos objetos (reflectância das superfícies), nem em uma exclusividade "subjetivista" (HARDIN, 1998), que considera as cores como produto de 
um processamento mental.

Assim, nos parece que introduzir ao aluno a complexa natureza da luz, nos marcos anteriormente colocados, contribui para a formação do raciocínio científico, embasado em um pensamento crítico, investigativo, dedutivo e indutivo e, principalmente, criativo. As importantes contribuições de cientistas como Hertz, Einstein, Bohr e Planck demonstram que a limitância das nossas percepções sensoriais não impede a decodificação de medidas e grandezas invisíveis a qualquer vidente, e, assim, conhece-se, por exemplo, o efeito fotoelétrico, indispensável conteúdo do ensino de física hoje em dia. Para além da importância pedagógica, portanto, uma nova prática educacional embasada em uma aprendizagem significativa no ensino das Ciências oportuniza o levantamento de questões que demonstrem alcances e limitações da ciência (SANDOVAL, J. D.; SANDOVAL, J. J., 1990), estimulando a apropriação e a criação científicas críticas do aluno.

Os resultados obtidos em nosso teste de associação livre de palavras, esquematizados em gráficos, não são ambíguos, e em nossa discussão demonstramos que as associações dos alunos (cegos e videntes) às cores evidenciam componentes multissensoriais. Percepções táteis, auditivas, gustativas, olfativas e emocionais, além das visuais, são mobilizadas no processo de aprendizagem das cores desde a infância, já que a estratégia para o ensino de cores na educação infantil é a associação.

Oposta a esta demonstração está a concepção no ensino de física de que cegos não compreendem cores. Ao chegarem ao $9^{\circ}$ ano do Ensino Fundamental, os estudantes cegos de nascimento sem percepção de cores de nosso estudo demonstraram possuir conhecimento prévio suficiente sobre o assunto, uma passo a mais para vencer uma das maiores barreiras no contexto do ensino de física para deficientes visuais: a barreira comunicacional (CAMARGO, 2010, 2012).

O ensino do tema "cores" a pessoas totalmente cegas de nascimento precisa de novas abordagens que permitam uma concepção multissensorial na construção dos significados, sejam eles sociais, sejam físicos, contribuindo tanto na formação desses indivíduos quanto na formação de professores de física inclusivistas. Mais do que tentar encontrar soluções à questão-desafio de nosso trabalho - "De que maneira deve se dar o ensino de cores para alunos totalmente cegos de nascimento?" (CAMARGO, 2012, p. 267) -, propomos outra questão que deve antecedê-la obrigatoriamente se quisermos tornar realidade o protagonismo discente: "O que alunos totalmente cegos de nascimento não podem aprender sobre cores?".

\section{NOTAS}

\footnotetext{
${ }^{1}$ A aluna que relacionou mesa à cor amarela relatou ter gostado muito de uma mesa amarela vista recentemente por ela.
} 


\section{REFERÊNCIAS}

BARBOSA-LIMA, M. C.; CATARINO, G. F. C. Formação de professores de Física inclusivistas: interdisciplinaridade por si. In: ENCONTRO NACIONAL DE PESQUISA EM EDUCAÇÃO EM CIÊNCIAS - ENPEC, 9., 2013, Águas de Lindóia. Atas IX ENPEC,: Águas de Lindóia, 2013, p. 01-08.

BERLIM, R. Jonas e as cores. São Paulo: Peirópolis, 2007.

BIANCHI, C. S.; BARBOSA-LIMA, M. C. A. Concepções de licenciandos em Física e a inclusão de deficientes visuais: a urgência de um novo paradigma com enfoque em CTS. In: ENECIÊNCIAS, 4., 2014, Niterói. Digita, Niterói: Universidade Federal Fluminense: 2014.

BRASIL. Decreto n 5.296. Regulamenta as Leis nos 10.048, de 8 de novembro de 2000, que dá prioridade de atendimento às pessoas que especifica, e 10.098, de 19 de dezembro de 2000, que estabelece normas gerais e critérios básicos para a promoção da acessibilidade das pessoas portadoras de deficiência ou com mobilidade reduzida, e dá outras providências. Presidência da República. Casa Civil. 2004

CAMARGO, E. P. A comunicação como barreira à inclusão de alunos com deficiência visual em aulas de Mecânica. Ciência \& Educação, Bauru-SP, v. 16, n. 1, p. 259-275, 2010.

. Saberes docentes para a inclusão do aluno com deficiência visual em aulas de Física. São Paulo: Editora UNESP, 2012.

CORNOLDI, C.; VECCHI, T. Cécité précoce et images mentales spatiales. In: HATWELL, Y; STRERI A.; GENTAZ, E. Toucher pour connaitre: psycologie cognitive de la perception tactile manuelle. Paris: Ed. PUF, 2000.

DANIEL, M; DAVID, D. Expérience tactile et capacités d'imagerie mentale des aveugles congénitaux. Bulletin de psychologie, Paris, Tomo 59 v. 2, n. 482, p. 159-172, mar.-apr. 2006.

DRIVER, R.; ASOKO, H.; LEACH, J.; SCOTT, P.; MORTIMER, E. Constructing scientific knowledge in the classroom. Educational Researcher, v. 23, n. 5, p. 5-12, 1994.

DUIT, R. The constructivist view in science education: what it has to offer and what should not be expected from it. Investigações em Ensino de Ciências, Porto Alegre, v. 1, n.1, p. 40-75, 1996.

FIOLHAIS, C. Os primeiros raios invisíveis. 2015. Disponível em: < http://ail2015.org/index. php/2015/08/11/os-primeiros-raios-invisiveis/>. Acesso em: 2 abr. 2016.

GOLLER, A. I.; OTTEN, L. J.; WARD, J. Seeing sounds and hearing colors: an event-related potential study of auditory-visual synesthesia. Journal of Cognitive Neuroscience, Norwich, Inglaterra, v. 10, n. 21, p. 1869-1881, 2009.

GUERRA, A.; REIS, J. C.; BRAGA, M. Uma abordagem histórico-filosófica para o eletromagnetismo no ensino médio. Cad. Bras. Ens. Física, Florianópolis, v. 21, n. 2, p. 224-248, 2004.

HARDIN, C. L. Color for philosophers: unweaving the rainbow. Indianopolis: Hacket, 1988.

HILBERT, D. R. Color and color perception: a study in anthropocentric realism. Stanford: CSLI, 1987.

LURIA, A. R. Diferenças culturais de pensamento. In: VIGOTSKI, L. S.; LURIA, A. R; LEONTIEV, A. N. Linguagem, desenvolvimento e aprendizagem. 10. ed. São Paulo: Ícone, 2006.

MAURI, T. O que faz com que o aluno e a aluna aprendam os conteúdos escolares? In: COLL, C. et al. O construtivismo em sala de aula. São Paulo: Editora Ática, 2006.

p. $79-122$

MATSUSHIMA, E. H. A questão ontológica da percepção da cor. Paideia, Ribeirão Preto, v. 11, n. 20, p. 59-66, 2001.

MERTEN, T. O teste de associação de palavras na psicologia e na psiquiatria: história, método e 
resultados. Análise Psicológica, Lisboa, v. 4, n. 10, p. 531-541, 1992.

MOLINA, L. Posso ensinar cores a uma pessoa cega? Guia Inclusivo. Setembro de 2013. Em: <http://www.guiainclusivo.com.br/2013/09/posso-ensinar-cores-uma-pessoa-cega/>. Acesso em: 15 out. 2014.

SANDOVAL, J. D.; SANDOVAL, J. J. S. A sensação de cor: um problema da Física? Algumas experiências para sala de aula. Cad. Cat. Ens. Física, Florianópolis v. 7, n.3, p. 183-195, 1990.

SARTRE, J. P. A imaginação. Porto Alegre: L\&PM, 2013.

SAVAGE, C. W. In defense of color psychophysicalism. Consciousness and Cognition, Atlanta, EUA, n. 10, p. 125-132, 2001.

SHEPARD, R. N.; COOPER, L. A. Representation of colors in the blind, color-blind, and normally sighted. Psychological Science, Chicago, EUA, n. 3, p. 97-104, 1992.

SOLER, M. A. Didáctica multissensorial de las ciencias: un nuevo método para alumnos ciegos, deficientes visuales, y también sin problemas de visión. Barcelona: Ediciones Paidós Ibérica, 1999.

VIGOTSKI, L. S. A formação social da mente. 7. ed. São Paulo: Martins Fontes, 2007. 1997. . El niño ciego. In: VIGOTSKI, L. S. Fundamentos de defectología. Tomo V. Madrid: Visor, . Pensamento e linguagem. Edição eletrônica: Ed. Ridendo Castigat Meres, 2001. Disponível em: <http://www.ebooksbrasil.org/eLibris/vigo.html>. Acesso em: 16 out. 2014.

Data de recebimento: $24 / 07 / 2015$

Data da aprovação: $12 / 04 / 2016$

Data da versão final: 18/04/2016

Contato

Cristina Bianchi

Universidade do Estado do Rio de Janeiro, Instituto de Biologia Roberto Alcantara Gomes.

Rua São Francisco Xavier - até 278 - lado par - Tijuca - Rio de Janeiro, RJ - Brasil.

CEP: 20550012 